\title{
Taoism and Confucianism as a Reflection of African Artistic Creation: The Case of Bamileke Art in West Cameroon
}

\author{
Djoukwo Tsanetse Majolie Carine ${ }^{1}$, Aihong Wang ${ }^{2}$ \\ ${ }^{1}$ International College Department, Jingdezhen Ceramic Institute, Jingdezhen, China \\ ${ }^{2}$ Department of Products Design, Jingdezhen Ceramic Institute, Jingdezhen, China \\ Email address: \\ L20180902@stu.jci.edu.cn (D. T. M. Carine), cdjoukwo@gmail.com (D. T. M. Carine) \\ To cite this article: \\ Djoukwo Tsanetse Majolie Carine, Aihong Wang. Taoism and Confucianism as a Reflection of African Artistic Creation: The Case of \\ Bamileke Art in West Cameroon. Arabic Language, Literature \& Culture. Vol. 6, No. 2, 2021, pp. 43-52. doi: 10.11648/j.allc.20210602.13
}

Received: June 1, 2021; Accepted: June 15, 2021; Published: June 25, 2021

\begin{abstract}
Rendered in Africa by curiosity, researchers have issued divergent opinions about the cultivation of different peoples. Some have been taken aback by the wealth of artistic production, while others believed that Africa did lack history. Father Engelbert Mveng reacted to these aberrations by arguing that the history of Africa is written in art and that we are so often uneducated before this writing. The Reverend Father wanted to represent the fundamental structure of works of art in Sub-Saharan Africa. The work of art in African artistic design does not simply reproduce nature as it is done in Western realism. It is more of a form of expression, a language, or a narrative being told. The two aspects gathered, namely the signifier and the signified, real and unreal, soul and body, are, in a sense, the different binomials that characterize traditional African art and give it existence. In other words, the existence of an artwork in Africa improves the moment these two elements are present. In Asia, there are two philosophical thoughts that, far from being completely contradictory, share a common foundation. It is in Taoism and Confucianism, that the concept of Yin and Yang is associated. These doctrines allow us to translate more concretely the concept of duality in African arts, which will be illustrated in this study by the art of the Bamileke people. Taoism is oriented towards eternal and supernatural values while Confucianism is cored and geared to human morals and ethics. Taoism here refers to the spirit of the work, on its unreal side while Confucianism referred to the body of the work, on its real side. The argument consists of two parts: first a comparative study between Chinese aesthetics and the aesthetics of the Bamileke people, then the convergence of thought that exists between the two cultures. Thus, Taoism and Confucianism are with Buddhism the foundation of the Chinese culture, making it a civilization that is needed under all heaven. As a result, the question is why African culture, despite having the same assets as its Asian counterpart, is still learning how to assert itself on the global art scene, despite its natural and human potential.
\end{abstract}

Keywords: Taoism, Confucianism, African Art, Local Culture, Bamileke

\section{Introduction}

Following the colonial era of the 1960s, Africans began to open up to the rest of the world. The openness allowed many significant changes to occur. There have been profound changes between traditional artistic production on the artistic level and carried out under foreign influence. Artists now apply themselves to representing forms according to Western aesthetic canons to represent reality as it is. However, such representations do not win everyone's approval on the ground because they are marginalised from the local cultural context. That is the case with the works of art that litter the public buildings in the Bamileke territory [1]

Indeed, most of them obey Western standards of artistic representation, where the artist endeavours to represent reality as we see it. Except that under these conditions, the work does not live because it lacks something: "A SOUL". African Art, in general, is not only the representation of 
reality; it is more the expression of thought, of an idea [2]. This observation leads us to say that in contact with the West, African art has become distorted.

The same cannot be said of Chinese art, which has remained true to its traditional ways of portraying "elegant" and stylised subjects over time. Instead, her art reflects the daily life of its subjects. The themes discussed, as well as the performance techniques, are not foreign to the Chinese. As a result, the works directly challenge them since they speak their language.

A close study of this art from the Far East reveals that it is an art that Taoist and Confucian currents have greatly influenced for over fifteen centuries. The goal of these philosophies is to lead the human being to achieve the ideal that he would gain by seeking his personal development to obey the laws he received from heaven following the philosophy of yin and yang.

The question is how Taoism and Confucianism through the concept of yin and yang materialise in African art [3]. In other words, what common thread can we establish between the Taoist, Confucian, and African conception of art? How do yin and yang correspond to notions of object and subject in African art [4]? The answer to this problem requires that we first focus on Taoism, yin and yang, Confucianism and their influence on Asian aesthetics in general and Chinese in particular. What are the African aesthetic landmarks in general and those of Bamileke art in particular? What future for African art?

\section{The Yin and Yang Aesthetics of Taoism and Confucianism}

Taoism [5], Confucianism and Buddhism are the three pillars of Chinese culture. However, given the purpose of this study, only Taoist and Confucian currents, the concept of yin and yang, will be exploited.

\subsection{Taoism and Chinese Aesthetics}

With its roots in ancient culture, Taoism is based on texts, including the Tao tö-King [6], by LAO TZU, Lie Tzu and the Zhuangzi by TCHOUANG TZU and is expressed through practices that significantly influenced everything. The Far East, and even the West since the twentieth century.

Raphael PETRUCCI [7] mentions that Taoism gives pride of place to the periodicity of phenomena such as the movement of the sun, the moon and the apparent movement of the stars, fixes the idea of number and harmony to which the moral law is attached to wit rights and duties. It is an abstract principle within this gigantic creation of which humanity is only one part. This conception expressed in the 12th century BC was to direct the development of Chinese thought [8] and, therefore naturally, artistic creation, in this case, painting, to the present day.

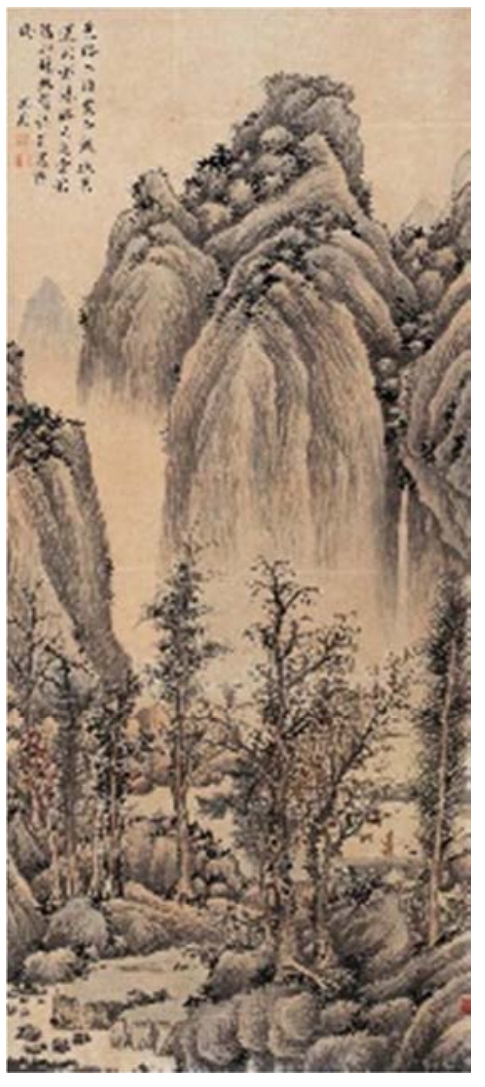

Figure 1. Traditional Chinese painting, Ming Dynasty.

The search for the universal soul, which appears in the rhythm of the physical world and the moral world, guides lovers of mountainside solitude to their contemplation, which is lost in immensity. (See painting above-Figure 1). Art itself will be imbued with this ancient doctrine; in its heyday, it will be nothing more than a prestigious commentary on this conception which is particularly powerful in the history of human thought.

Taoism advocates withdrawal from the activities of the world. It is because he retreats into the mountainous solitudes that the artist can contemplate and represent vast perspectives, the hazy horizons of the plains in a permanent quest for "The Universal", the "Eternal", and the "Unnameable" [9]. This philosophical current, so to speak, has remained at the very source of all interpretations of the landscape.

In addition, SIE HO, a Chinese critic and painter from the end of the 5th century, formulated the six rules or the six canons which have governed Chinese aesthetics from that time to the present day.

1. Vitality of the work expressed by spiritual consonance.

2. Using the brush in a well-structured way.

3. Fidelity to the object in the representation of shapes.

4. Appropriate distribution of colour.

5. Composition according to the hierarchy of objects.

6. Transmission of models from the past in making copies.

It is the conception of the Tao that is at their base. Raphael PETRUCCI comments that the consonance or rhythm of the 
mind is the creative element of the movement of life. Its perpetual flow is but a tangible manifestation of this rhythm that fills the immensity. The harmonious movement of the mind brings about the perpetual flow of things.

They would vanish into nothingness if he had to stop. Therefore, the painter must perceive above all through the movement of forms, the rhythm of the spirit, the cosmic principle that they express. Beyond appearances, he must grasp the meaning of the universal.

Nevertheless, when he has grasped the real essence of the elements of the world, he must enter the folds where the Tao hides, at the very bottom of beings and things. The law of bones, employing the brush, is the adequate expression of the internal structure. The painter thus evokes the meaning of the tangible thing.

After having discovered the deep meaning of appearances in the link which links the rhythm of the spirit to the movement of life, after having conquered the possibility of expression by touching the essentials of the internal structure, he can end up representing the form in its conformity with the beings who inhabit the world. This formula corresponds to a very old conception of Chinese philosophy. The perfect conformity of a being with his nature or with the principle of universal order which is in him and which constitutes, when applied to man, the Chinese idea of Holiness. By this conformity, man, the saint, becomes the equal of Heaven and Earth.

Through this conformity, the painted form takes on more than the value of a simple representation. It becomes a true creation and, using the work of art, is realised in the very principle of Tao. For each being or thing represented, being by its nature, the work of art becomes the image of a perfect world where the essential principles are balanced in harmonious proportion. The application of SIÉ HO's second and third principles led the painter to study what was essential in forms. Thus, this explains the vigorous power of synthesis specific to the technique of Far Eastern representations.

As a consequence of this search for the conformity of beings or things with their essence, the formula of the fourth principle intervenes. The essential structure is detected, the perfect form is defined, it remains to distribute the magic of the colour according to the essential similarity of these beings or these things. The colour comes to take with its own life a structure where the eternal principles and the action of the Tao have already emerged. She too must evoke, in her measure and her choice, the elements revealed. When these conceptions are well established on the individuality of forms, the whole composition comes into play. She must arrange the lines that cover the space of the painted surface observing the immanent laws of Tao; a philosophical subordination is established from one to the other, one place and one is suitable for the expression of the spirit. The harmonious principle of the universe finds a final expression here.

When he thus realised the Tao in the entire work, the artist made a true work of creation. Thus, the artist propagates an absolute of perfection that passes through the works where this ideal is repeated, resounding from one master to another like the echo of a giant voice whose nobility and gravity resonate in the immensity of the world, which is the philosophy that emerges from the six principles of SIÉ HO.

While LAO-TSEU despises the narrow domain of man and gets lost in the infinite, K'ONG TSEU, on the contrary, with a severe gesture, dismisses those speculations which he considers useless on metaphysical matters beyond human understanding. He is attached to those relationships that LaoTse considered inferior and secondary.

\subsection{Confucianism and Chinese Aesthetics}

Confucianism is one of the greatest philosophical, moral, political and, to a lesser extent, religious schools [10] in China. History tells us that it developed for more than two millennia from work attributed to the philosopher KONGFUZI, "Master Kong" (551-479 BC). Confucianism has been and still is the true foundation of Chinese culture. The writings of XU FUGUAN [11] (disciple of Confucius) introduce us to the Confucian view of aesthetics. In his book on "the artistic spirit", he starts from the well-known observation that, in the Confucian cradle of aesthetics in China, art is understood as an integral part of being in society, of the constitution and ethics of the individual. By "ethics" in the broad sense, he understands everything that concerns behaviour, that is to say, human conduct in the world and in front of other humans, its practice as well as its theory still encompassing reflection on "good life" [12].

Subsequently, he shows how it is, on the other hand, the "fasting of the heart", xin Zhai, in one of the major sources of philosophical Taoism (Zhuang Zi), which as an existential attitude and a mode of life from antiquity became the ideal condition in the field of artistic and aesthetic practices in China.

An established morality can imperatively regulate human behaviour in a certain society. By "aesthetics", also taken in the broad sense of the term, is understood everything relating to perception as behaviour and all the phenomena of artistic activity and reflection on these multiple subjects.

In short, the TAO of the Taoists takes its source in the principle of heaven. This essence generates the operative action of the cosmos, while, among the Confucians, the TAO corresponds to practical morality, which is none other than the rule of conduct in life. Thus, Confucius situates men in a moral universe in which the order of the earth responds to the order of heaven. 


\subsection{Yin and Yang and Chinese aesthetics}

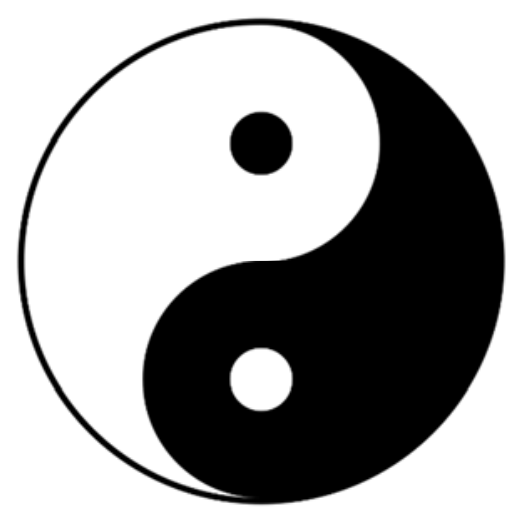

Figure 2. Symbol of yin and yang.

In Chinese philosophy, Yin and Yang [13] (Figure 2) are two complementary categories used to analyse all phenomena of life and the cosmos. These two notions, far from being antagonistic, complement each other for balance and productivity in existence. In the artistic field, too, this antagonistic concept has always existed, thus governing the conception and realisation of Chinese artistic productions.

Chinese art critics recognise two different tones in the work of art: thus, we can read a critic from the end of the 17th century:

"I have heard that the reality (dao) of heaven and earth lies entirely in these two concepts yin and yang, strength and gentleness (gang ruo) (16b). Literature is the epitome of what exists in the universe because it is the expression of Yin and Yang, strength and gentleness. Only the words of the Sage realise the union of these two vital impulses without privileging one over the other. However, even in the book of Changes (Yijing) or the Analects of Confucius, (Lunyu) it is possible to separate these two aspects differences in training that are related to the time or author. Since then, writers have all emphasised one aspect or the other. The writings which relate to the Beautiful through the yang - of the force - are reminiscent of thunder, of lightning, of the long roar of the wind rising from a valley, of the tops of the mountains, of the abrupt precipices, of the overflow. great rivers, at the gallop of a steed; movement analogous to that which leads us to climb on an author to look into the distance; evocation of a king of drums leading into combat ten thousand warriors. The writings that relate to Beauty through yin - softness evoking the sun rising on the horizon, a light breeze, a cloud, a twilight glow, a vapor, a secluded forest, a meandering torrent, wrinkles on the surface of the water, eddies, the brilliance of Jade or a pearl, the cry of a wild goose being lost in the silence of space. They are like a deep sigh, like the distant flight of thought, like sweet joy or sadness on the face. "[14]
These writings present the concept of Yin and Yang as the true pillar of Chinese aesthetics. A concept which in itself incorporates a duality. African art theorists are unanimous in saying that there is a more or less similar duality in the artistic expression of the said continent.

\section{Some African Aesthetic Landmarks in General and Those of Bamileke Art in Particular}

In the African tradition, said Reverend Father Engelberg MVENG, Man, the last of the descendants of all beings to whom God has given life, had the privilege of having the word and being the sponsor of all created things before him. To do this, he calls everything by a name and gives it a mission, a charge, which was the beginning of the symbolism through which Man sees a way to pose his problems and solve them himself. The body, in this symbolic dimension, appears as the first sign language set in motion. It reads in two ways: first as an expression of physical reality and second as a means of giving meaning to an invisible reality.

It is by starting from such a conception of reality that the African artist manages to give life to an object. Thus, we translate the creation of African works [15], from which the Cubist artists were inspired to establish different bridges between modern arts and "primitive" arts. This process takes into account two closely related moments. These are the nomadic moment and the tectonic moment, distinguished by Carl Einstein in his essays on African sculpture.

This step he took is based on a very old model of culture. It is through this model that man apprehends his reality of the world. The art object in this context is only a means of materialising thought. It not only makes it possible to archive the founding elements of a belief system but, above all, to structure thought in visible forms to establish links between the physical and psychic world. Thus, African sculptors realised that the body, in the course of action, calls upon two systems: one of the visual and the other of the construction of human thought.

\subsection{Some African Aesthetic References}

In the Ethiopia Review [16], Iba NDIAYE DIADJI presents three main landmarks of African aesthetics, namely:

1) The sense of composition

When we have the opportunity to contemplate African art, we are immediately amazed by the composition of art, whether it is a poem, a tale, a sculpture, performance or any other form of artistic expression. There is no domain, he says, where the "negro" does not pose with particular rigour an order in work, an order of composition which is not exactly that of nature, nor precisely the fruit of chance. However, the 
composition in the work of art immediately catches our attention, which gives the work that breath by which it communicates to our senses; this is how Picasso, Matisse and Braque were won over by the "simplicity" of art the composition of African works.

2) The taste of the diversity

The mix between the different forms of expression and artistic techniques should be remembered as one of the characteristics of African artistic creation [17]. It is rare, if not impossible, to find an African artist inspired by only one form of expression. Senghor [18] edifies us in this regard in Camara LAYE's book The Black Child. He emphasises that in Africa, the arts are linked to each other. The paintings are approaching sculptures, the tapestries becoming both painting and sculpture, among others. In Africa, art integrates the daily activity of man. While singing, we work in the peanut fields; we accompany the tam-tam song with preparations for a wrestling fight. This connection of art forms with each other and with life has led to it being said that African art is social and functional and that here "art for the sake of art" does not exist.

3) The local colour

Local colour refers to the personality of the social group to which the artist belongs; a natural consequence of the physical environment, habits and customs, and beliefs deeply mark men who have experienced the same influences for several generations because each social group is concerned with the balance of the community accepted works of art that met its aesthetic-ethical canons, and then disseminated them on behalf of all. The work appreciated collectively thus became the property of the group and, by extension, its identity mark. However, the author has two objections to these benchmarks.

First, these different aspects are not specific to African art since each person is attentive to the correct composition of the work, the contribution of mixed techniques for more expressiveness, and its local colour because he cannot do otherwise. Then, the second objection could relate to the aesthetic relevance of the concept of "African art" that Western aestheticians and ethnologists have long qualified as "Negro" art, produced by "primitive" and backward peoples without history, which is an aberration because as Reverend Father Engelbert MVENG [19] said, the history of Africa is written as a work of art, but more often than not we are illiterate in front of its writing.

Iba Ndiaye believes that "Africanity" is carried within you and that African artists [20] would benefit from emphasising their full membership in Universal Art without a pejorative cliché. If African people are proud of their culture and ready to brandish it in all skies, it is the Bamileke people of West Cameroon.

\subsection{The Aesthetic Landmarks of Bamileke Art}

1) An art reminiscent of the movement

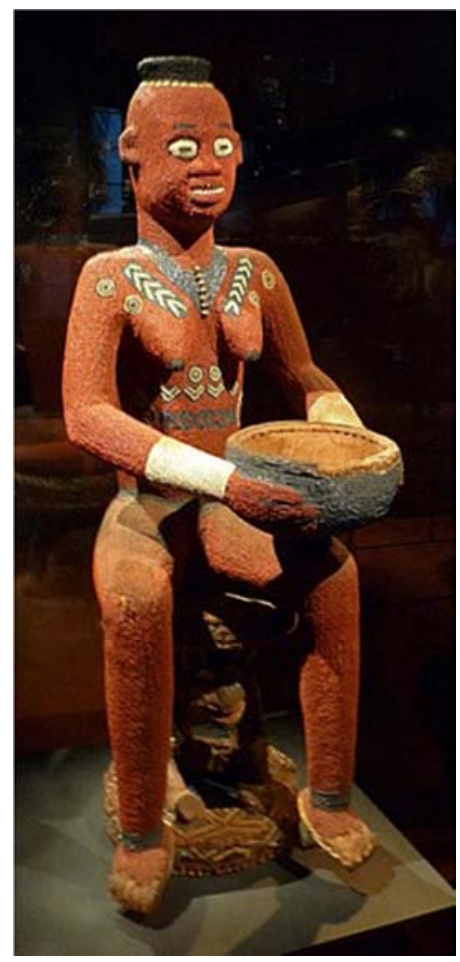

Figure 3. Queen carrying the Bamileke cup, fr.wikipedia.org.

Originally from the high plateaus of western Cameroon, the art of the Bamileke people linked to the Bamoun group has several particularities. The sculpture and the realisation of masks and beadwork on statues and furniture constitute, among many others, techniques mastered by the various peoples of what was called the Grassland to which they belong. Here, the artistic realisations evoke tales, describe the phenomena of life. In addition, they have a communicative aspect and a very rich universe of masks; unlike many African statues, Bamileke statuary has the particularity of recalling movement; that is to say that they evoke an action which can, for example, be translated by the posture of the statue. Thus, we have the example of a princess carrying a cup (Figure 3).

The sculpture is closely linked to the beadwork and gives the objects aesthetic advantages, which are the fruit of rather elaborate research and which is devolved to the workers ("Large chief's seat, covered with pearls with phantasmagorical characters seeming from beyond, true surrealist appearances, this is, we think, one of the most impressive combinations of form and color" [21]), confer Figure 4. The seats are, for example, reserved for high dignitaries of the chiefdom. Therefore, they will be more or less abundantly decorated according to the hierarchical status occupied. Thus, the higher the rank, the more decorated the seat. 


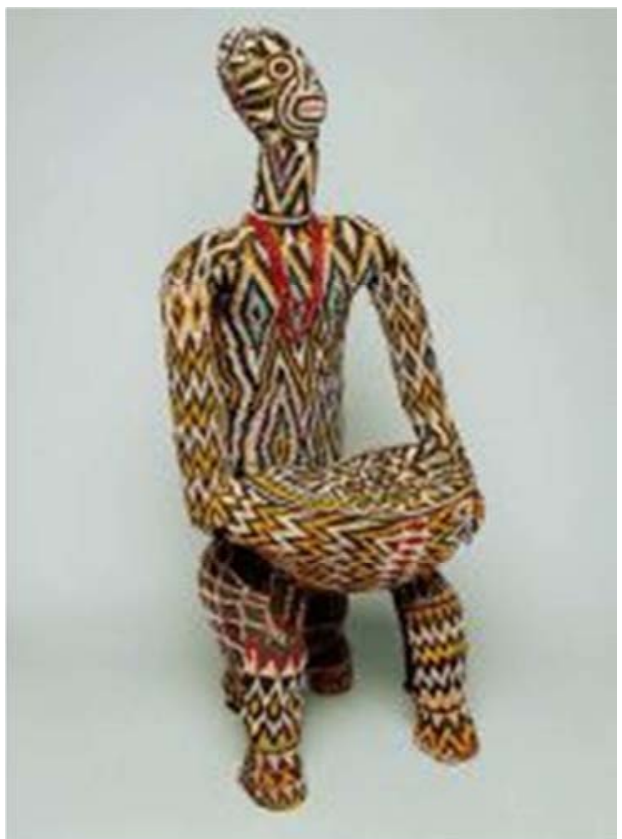

Figure 4. Beaded seat, reserved for the chef, Bamileke, galerie-artafricain.com.

Still, on the subject of the sculpture of the Bamileke people, Marie-Louise Bastion affirms that the forms swell and distort. There is an attempt to translate the movement into limbs that stretch out disproportionately, sometimes by asymmetry. The physiognomies are imbued with dynamism, rendered by the masses' outrageous balance, which combines in a beautiful architectural construction. Extraordinary combinations equate the human being with the animal kingdom, chosen for its symbolism.

Also, the extraordinary wealth of Bamileke plastic production is made up of adornment, textiles [22], and conglomerate art [23], among others. Here the best-known pictorial representation is physical and can be observed during certain rituals or festivities in the public square.

2) A particular architecture

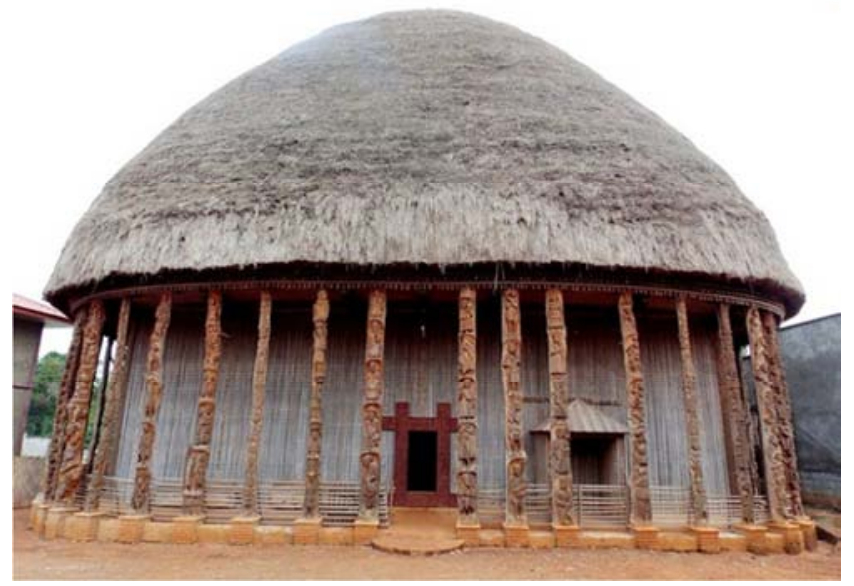

Figure 5. The traditional Bamileke architecture, Nofi Media.
The Bamileke architecture is quite atypical and responds to very complex social rules. Indeed, depending on the status one occupies within the chiefdom where one will live, it will be different; that is, it will have its architecture. Thus, the vaulted-roof architecture is reserved for the village chiefs and notables (Figure 5).

3) The trend towards the geometrisation of shapes

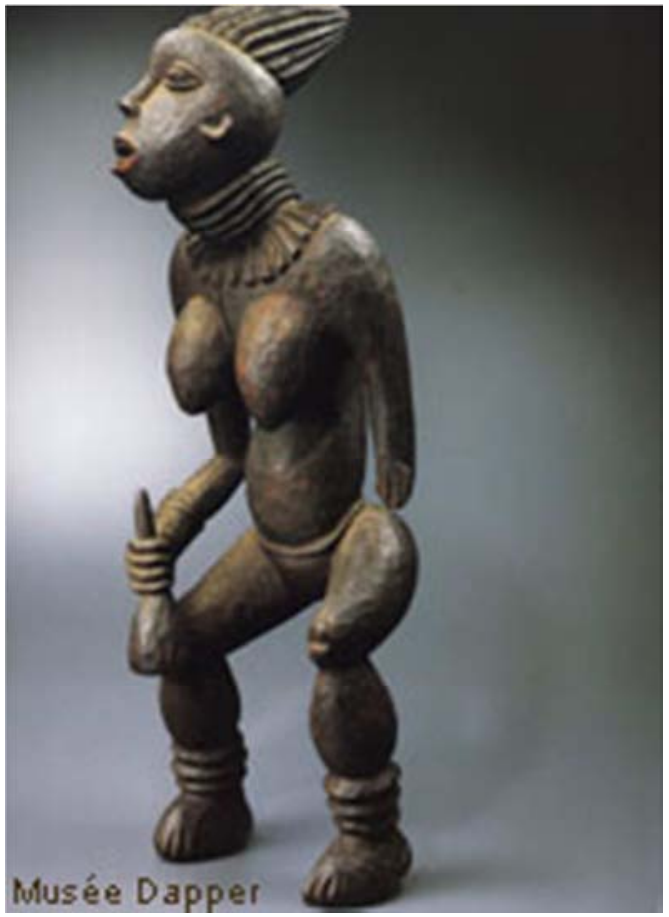

Figure 6. PRINCESS BANGWA, Bamileke, Walker Evans, American, 19031975.

Faced with the diversity and sometimes the rare quality of Bamileke art objects still present in the chiefdoms as support and expression of the chief's authority, one immediately feels the impression of complex symbolism and spirituality. The combinations, the abstraction, the geometrisation of the painted, braided, chiselled or sculpted figures. Everything shows that art is the essential activity of this civilisation, sculptural art, particularly the most widespread form of artistic expression.

The tendency to geometrise forms predominates in Bamileke art in general when compared to other styles of Grassland. It even constitutes one of its specific aspects. In addition to very strong realism, a tendency to purify and simplify, or on the contrary to amplify certain forms, appears in many works [24]. For example, it can be seen on Princess Bangwa, Bamileke (Figure 6).

By their symbolic and functional character, these works bear witness to African spirituality relating to human existence. In Africa, life and death are linked, inseparable; however, the ideology of life takes precedence over that of death, that is why the different artistic expressions exalt the 
victory of life over death, in a surge of eternity; this eternity to which all men aspire, including the followers of Taoism and Confucianism [25].

\section{Taoism, Confucianism, Yin and Yang in African Art}

This section considers Taoism and Confucianism as two opposing but complementary philosophical currents, like yin and yang. The first is essentially focused on metaphysics, the supernatural, the eternal, while the second is centred on man, personal development, and relationship with others. The duality to which we are referring emerges from African artistic expression in general, where the object of art is made up of a Body and a Soul. Finally, we link these two Asian schools of thought to the African philosophy of existence to show the convergence of thought between the two cultures.

\subsection{Convergence on a Philosophical Level}

In Chinese cosmogony, heaven is the primordial substance from which the universality of beings may have arisen; [28] then, to explain the series of various formations, we introduce the female principle and the male principle, Yin and Yang, whose action gives to the interdependence and succession of phenomena the character of generation. In contact with Tien, Heaven, the primitive representation of the inexplicable Yin and Yang, male and female principles, have kept their nature undefined and without limits. These two notions, far from being antagonistic, complement each other for balance and productivity in existence.

The African, too, engaged in a fight for life, integrates this existential duality. Indeed, in its conception of things, each living being has a soul, and for the soul to live, there is a need for a body. Also, everything created is "life"[26] and participates in life: a life desired and maintained. In the being of what exists, there is the living force. Strength and being are intrinsically linked. Hence the African artwork of body and mind, two entities that are not of the same nature but essential for there to be life. The African philosophy of existence is similar to the Chinese one of yin and yang, and Chinese painting joins African painting, founded on the notions of symbol-reality, object-subject, real-unreal, soulbody in artistic representation.

\subsection{Convergence on an Artistic Level}

In Chinese painting, "the depth of meaning", or even the meaning "as depth", come to be expressed through the pictorial epokhe (phenomenological reduction) of the representation and its meaning or meanings. [27]

This study aims to show that the concept of yin and yang found in Taoism and Confucianism integrates both the symbolic aspect and the reality aspect, objectivity and subjectivity, the unreal and the real, the form and the idea in the African work of art.

Tao of Taoists has a source in the principle of heaven. This essence generates the operative action of the cosmos, while, among Confucians, the Tao corresponds to practical morality, which is none other than the rule of conduct in life. Thus, Confucius [28] situates men in a moral universe in which the order of the earth responds to the order of heaven.

Following the phenomenological approach, art cannot be reduced to its purely aesthetic aspect. On the contrary, it attests to dimensions that no aesthetic can ever exhaust because it concerns, above all, the relationship of man to the world around him.

In African art, works are particularly complex, both aesthetically and ethnologically. Each object must be studied considering its environment because it is part of a set of "expressions that complement and respond to each other".[29]

Taoism and Confucianism through yin and yang, and because they refer to the object and subject in art, bring together the two sets necessary to create an African work of art. So Einstein [30] translates when he talks about the nomadic moment and the tectonic moment in art.

The object and subject in art were approached by Emmanuel Kant [31]. Speaking of objective Beauty, he considers that a thing is beautiful because it has certain objective characteristics that make it beautiful. This is what we maintain whenever we say that a thing is beautiful for such or such a reason: these reasons expose the qualities which make that thing beautiful.

If they are objective qualities belonging to the object, they must be observable and measurable as such. The harmony of shapes, colours, sounds, verses, parts concerning the whole, a harmony which can depend on proportions, symmetry as opposed to the deformed, the shapeless, the disproportionate, the unfinished, the unbalanced.

Subjective Beauty is translated from the ideas according to which there are a variety of taste judgments irreducible to blindness and the lack of idea of what is beautiful; It is not possible to confine artistic creation in the reproduction of models and obedience to the canons of Beauty without killing all kinds of creation and reducing it to a craft.

In short, Kant is the first to show the autonomy of art and reconcile objectivity and subjectivity in art: objectivity because of the presence of content in work, and subjectivity because there is taking into account the artist's creativity. KIM CHÔNG-HÙI [32] gives us an illustration of this in Chinese calligraphy when he says that one should write only according to the idea and the prompting of the moment. This means that a true creation can only be realised when the ideas, which the artist wants to express, agree with the fleeting excitement. 
Objectivity and subjectivity are verified in African art because works of art are witnesses of something: history, techniques, forms, functions, and often of many things. They talk about soil, plants, materials, the dead, the living, spirits, animals, to name a few. Here the Beauty of a work of art is not defined by Western standards of Beauty, but work is beautiful because it has a certain function, which is religious.

In African artistic production, "The Negro artwork expresses, by nature, an idea or sentiment-image [33]: a symbol." [34] This development leads us to say that African art has a very close relationship with Chinese art.

\subsection{Convergence Linked to Artistic Practice as an Aesthetic Experience: The example of Chinese Yi Jing and Kè Among the Bamileke}

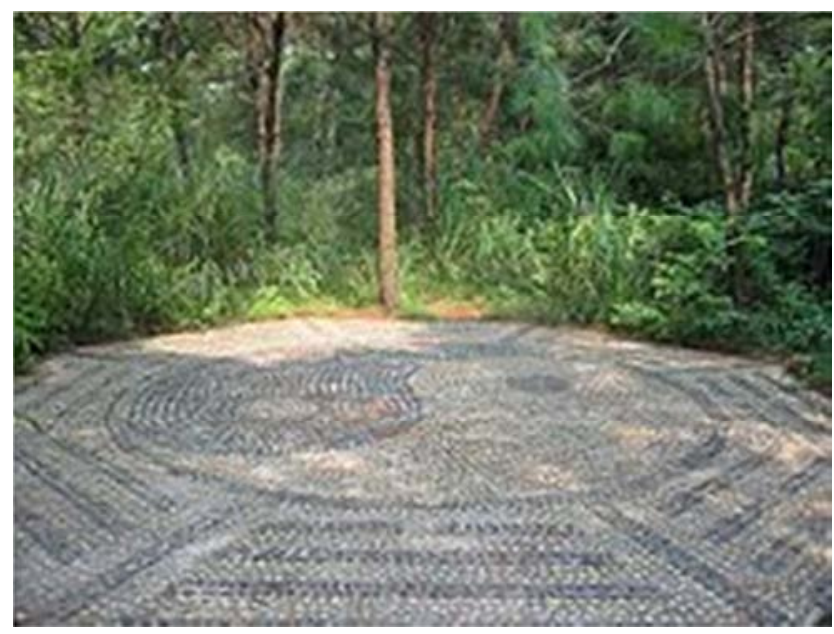

Figure 7. Yi Jing is often represented by the "Taijitu" surrounded by the eight trigrams, Yi Jing-Wikipedia, fr.wikipedia.org.

The Yi Jing [38] or "Classic of Changes" is a work that is both an energetic map of the world and a divinatory practice accessible to anyone wishing to experience it. Moreover, it is a book that allows you to live serenely in a fickle world since it explains all-natural and human phenomena.

In Chinese thought, the first law of this world is change (day/night, summer/winter, birth/death, time of peace/time of war, time of plenty/time of scarcity and others). Therefore, not only can one not escape change, but pretending otherwise is the surest way to make oneself unhappy.

So, if there is to change, the best question to ask is what posture and what action to take to avoid this being a source of anguish and lead the most serene and happy life possible in a fickle world. There are 64 postures symbolised in 64 hexagrams that describe the phenomena of life according to the aspirations of the user. The "Taijitu" (Diagram of the cosmological scheme) to which we also attribute the symbol of Yi Jing [35] gives an overview of these different postures. You can see it in this representation (Figure 7).

Whether for daily life, agriculture, internal or external politics, the Chinese consult the Yi Jing [36] as the Greeks would consult the Pythia. Questions such as When should I sow?, How should I deal with this rival?, and What is the strategy for this war? are addressed using this system. According to this conception, success or failure never really depends on the act but the timing. There will be a time to sow, a time to reap, a time to face your rival, another to keep your back. A time to attack, a time to defend. This ideology faithfully reflects what characterises the phenomenon of kè among the Bamileke.

The kè, by its nature and its manifestations, relates to both magic and religion. SAVARY describes it in these terms:

"There are among the Bamileke a large number of rites intended to maintain the fertility of the group, which are addressed either to the ancestors or to the local deities. All of this necessarily leads to magical acts or practices, inseparable from religious beliefs. Proof of this is, for example, that the term which is used to designate everything that has a magical side, represents at the same time an important agrarian rite and the rite of passage for adolescents ".[37]

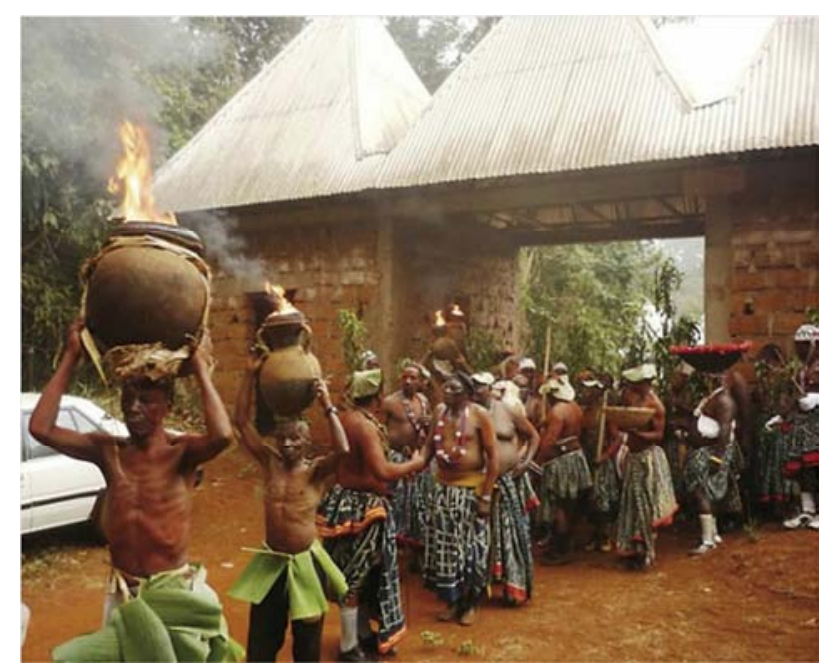

Figure 8. The official exit of the initiates to the power of kè among the Bamileke, Bamileke/Visiting Cameroon, www.editions2015.com.

The Bamileke has built a whole organised universe where the supernatural must comply with hierarchy and community rites. The magico-religious atmosphere in which works of art are bathed is one of the main conditions for their creation and one explanation for their end.

The symbols evoked at the level of the plastic arts (but also of rites, songs, dances, gestures, music) demonstrate the eminent place of the main problem of man, his passage from life to death and his confrontation standing with the forces of the cosmos [38]. Prisoner of these two deadlines, birth and death, man, to survive, or sometimes to live better, has allied himself with animals or more generally with the forces of nature.

For Jean-Paul NOTUE [39], a specialist in Bamileke art, 
the $k \grave{e}$ is a magico-religious phenomenon, a fundamental aspect of the nafo (Bamileke royalty) and an important basis for social organisation. The kè is a transcendent and dynamic power, a diffuse force that evokes several aspects of the same reality, of the same phenomenon, according to the context of its applications.

Thus, the kè is:

1. The supernatural power of life and fertility that appears during the biennial celebration bears his name, as can be seen above (Figure 8).

2. The power to possess a double and transform oneself, in case of necessity, into an animal.

3. The power to detect evil forces and drive them away.

4. The power of healing and divination.

5. The power which founds the mystical force of the ' $F o$ ' (group leader), of the nine notables of the members of certain secret societies.

6. The power to make or stop the rain, to throw lightning, to divide a course.

7. The power to force the normal course of things a little for both good and bad.

The Bamileke believe that any element of creation [40] (plants, men, animals, to name a few) and, more generally, the constituent material of beings and things contains energy. This dynamic and supernatural power can be compared to that which under- stretches life itself. The concentration of this power (the driving force of the kè), which can increase or decrease, varies from one being to another, from one thing to another. Hence a hierarchy between the elements of the creation concerning the concentration of this power.

In short, it must be said that the kè, as well as the Yi Jing, have something in common: the expression of a certain invisible and immaterial power. The kè is neither a god nor a spirit. His spectacular actions define him. The theory of powers, of transcendent force, is general in Africa, but its nature differs from one region to another.

\section{Conclusion}

In Chinese philosophy [9], Yin and Yang are two complementary categories used in the analysis of all phenomena of life and the cosmos. They are not in any way substances, nor "forces" or "energies", but they are phrases to qualify the different components of a duality, generally opposed and complementary. It is a concept underlying Taoist and Confucian theories [41], hence its importance in the Asian cultural universe. It was a question of showing that these two philosophies in the image of yin and yang embody the two aspects that characterise the African work of art [42], namely the soul and the body of the work, the object and the subject of the work among others.

Thus, we have two cultures that have had the same predispositions to reach growth; however, one wonders what is at the origin of the phenomenon of acculturation observed in African art. Slowly and gradually, it lost many of its landmarks while Chinese art improved Chinese culture despite openness to foreign countries. Nevertheless, it has retained the authenticity of its signs and symbols, of its criteria of representation. How to explain this phenomenon in Africa? What future for African art? How and in how long to achieve Chinese cultural fertility? What to do so that artistic Africa takes shortcuts to make itself better appreciated, to be better heard like the other artworks of the planet, by the other peoples of the planet? There is still time for Africa to participate in the advent of the intangible culture of the virtual planet because it is based on a crossbreeding of cultures and artistic experiences.

The African artist Iba NDIAYE Diadji maintains that Plastic Africa, by its sculpture, its painting, its poetry, its dances, will find in the age of the audio-visual [43], the ideal time to flourish, establish and maintain continuous communication with the world. The urgency of associating African artistic production with new information and communication technologies is inescapable today; for a good reason, there is a kind of storm that is sweeping down physical boundaries and opening up new horizons for artistic creativity, for aesthetic taste [44], but also to face other questions in life. Therefore, we must face the situation not by fatalism harmful to the affirmation of a quality personality but by confidence in the possibilities of African languages to consolidate the nobility of rewriting arts, for example.

\section{References}

[1] Celestin Kaffo, Chapgang Noubactep, Judith Cynthia Akamba Bekono and Herve Tchekote, 2019, Funeral Ceremonies in Western Cameroon: Between Changes in Societal Practices, Reconstruction of Local Economies and Spatial Planning, In Spatialities and Funeral Practices, https://do.org/10.4000/gc.12127, p. 13-32.

[2] SENGHOR (L.S.), 1969, Négritude, Arabité, Francité. Reflections on the problem of culture, Beirut, p. 10.

[3] Marlene-Michèle Bitton, 2020, Drouot Hotel and African Art (1945-1960), Editions L'Harmattan, p. 140.

[4] Franziska Bolz, 2018, African Art, Könemann.

[5] Elizabeth Reninger, 2020, Taoism for Beginners: Understanding and Applying Taoist History, Concepts, and Practices, ROCKRIDGE Press, p. 164.

[6] Catherine Despeux, 2018, Taoism and Self Knowledge: The Chart for the Cultivation of Perfection (Xiuzhen tu), BRILL, $p$ 312 .

[7] Raphael PETRUCCI, 2004, THE PHILOSOPHY OF NATURE IN THE ART OF THE FAR EAST (1872-1917), You-Feng Bookstore, September, p. 160. 
[8] Leon Vandermeersch, 2019, what China teaches us. On language, society, existence, Editions Gallimard, p. 184.

[9] Joël Thoraval, 2021, Writings on China, Sébastien Billioud, Laure Zhang-Thoraval, Maurice Godelier, CNRS, p. 573.

[10] Edmund Kee-Fook Chia, 2020, Confucianism and Christianity: Interreligious Dialogue on the Theology of Mission, Routledge, p. 222.

[11] Mathias Obert, THE AESTHETIC THOUGHT OF XU FUGUAN (1902-1982), De Boeck Supérieur | "International review of philosophy".

[12] Michael R. Slater, Erin M. Cline, Philip J. 2020, Confucianism and Catholicism: Reinvigorating the Dialogue, University of Notre Dame Press, p. 272.

[13] Cyrille J.-D. January 2018, Yin Yang: The dynamics of the world, Albin Michel.

[14] Yao Nai (1731-1815), 1970, quoted in Overview of Chinese Literary Criticism (Zhonggxue Wenxue Pipingshi Dagang), Taibei, Kaishu shudian, p. 351 and 352.

[15] Mrinal Mitra, 2020, Color World Culture: African Art \& Oceanic Art Volume 1 de Color World Culture, Independently Published, p. 42.

[16] Iba NDIAYE, NEGRO-AFRICAN REVIEW OF LITERATURE AND PHILOSOPHY, AFRICAN ARTISTIC CREATIVITY UNDER THE STORM OF GLOBALISATION, NUMBER 63.

[17] Constantine Petridis, 2020, Speaking of Objects: African Art at the Art Institute of Chicago, Yale University Press, p. 216.

[18] SENGHOR, L. S., 1964, Liberty 1 - Négritude et Humanisme, Paris; threshold, p. 206.

[19] MVENG (E.), 1980, African art and crafts, Clé, Yaounde, p. 36.

[20] Ugochukwu-Smooth Nzewi, Thomas Fillitz, 2020, Dak'Art: The Biennale of Dakar and the Making of Contemporary African Art, Routledge, p. 232.

[21] MEAUZE (P.), 1967, L'art nègre, Hachette, Paris, p. 11.

[22] Francine Ulrich Awoung Sonkeng and Jules Kouosseu, VIII-1 2020, Ecomuseum: An international expansion, The "Ndop" Fabric. Manufacturing Process In West Cameroon: Between Tradition and Modernity, In Journal of the History of Technology, https://do.org/10.4000/ephaistos.7739.

[23] Christmas Lavallère Betga-Djenkwe, VI-2 2017 | 2018, Defense Technics of the West Cameroon Bamiléké Chiefdoms from the Xvith to XXth century, the Diversity of African Technical Heritage, In Journal of the History of Technology, https://do.org/10.4000/ephaistos.3289.

[24] M, L, Bastin, 1986, Sculptural Art of Bantu Africa, in Muntu, number 4-5, pp 137-164, cited by J-P, Notué, and L, Perrois, 1997, karthala. Orstom, p. 131.

[25] Shaun O’Dwyer, 2019, Confucianism's Prospects: A Reassessment, SUNY Press, p. 288.

[26] Marcel Anganga, 2011, African Theology and Life, Volume 19 , number 1, p. 87-106.
[27] Geneviève Hebert, 1991, Art and phenomenology. Collective work edited by Eliane Escoubas. Brussels, Rev. La part de l'oeil, Issue 7, 21x29, 271p; 800FB.

[28] Xiufeng Liu, Wen Ma, 2018, Confucianism Reconsidered: Insights for American and Chinese Education in the TwentyFirst Century, SUNY Press, p. 256.

[29] SCHWEINFURTH, G., In the heart of Africa, 1868-1871, voyages and discoveries in the unexplored regions of central Africa, Hachette, p. 1875.

[30] Carl Einstein quoted by Isabelle Kalinowski, "Presence of works and treatment of space according to Carl Einstein", article forthcoming.

[31] Emmanuel Kant, 1980, Philosophical Works, t, I, Paris, Gallimard, "la Pléiade", p 887.

[32] Ann-Baron Ok-sung, 1990, Some characteristics of the painting of scholars in Korea, compared to China. In: Asian Arts, tome 45, pp. 97-113.

[33] Kendell Geers, 2020, IncarNations: African Art as Philosophy, Silvana, p. 128.

[34] Dominique Bonpaix, 2015, "Le Yi Jing pour les Nuls", First éditions.

[35] Serge Augier, Philippe Lécyer, 2018, Tao Practical Encyclopedia: Health, Energy, Meditation, Feng Shui, Yi Jing, Flammarion Quebec, p. 605.

[36] Sarah Bartlett, Feng Shui Plain \& Simple: The Only Book You'll Ever Need, Copyright (C) 2010, 2018 by Sarah Bartlett, p. 149.

[37] SAVARY (C.), 1980, Cameroon, arts and cultures of the peoples of the West, ethnography museum, p. 28.

[38] Bennetta Jules-Rosette, J. R. Osborn, 2020, African Art Reframed: Reflections and Dialogues on Museum Culture, University of Illinois Press, p. 392.

[39] Jean-Paul NOTUE, 1988, THE SYMBOLIC OF ARTS BAMILEKE (WEST-CAMEROON): HISTORICAL APPROACH AND ANTHROPOLOGICAL, THESIS FOR THE Doctorate OF THE UNIVERSITY OF PARIS 1.

[40] Josue Simo Sop, 2019, Skulls and facial masks in the funeral rites Bamilekes, In Tradition and News. Life Sciences [Q-Bio], ffdumas-02389563F.

[41] David Hinton, 2020, China Root: Taoism, Chan, and Original Zen, Shambhala Publications, p. 176.

[42] Joshua I. Cohen, 2020, The Black Art Renaissance: African Sculpture and Modernism, University of California Press, p. 304.

[43] Sidney Littlefield Kasfir, 2020, Contemporary African Art, Volume 0 de World of art, Thames \& Hudson, p. 303.

[44] Wole Soyinka, 2020, Beyond Aesthetics: Use, Abuse, and Dissonance in African Art Traditions, Yale University Press, p. 160. 